\title{
Gene Expression Browser: large-scale and cross-experiment microarray data integration, management, search \& visualization
}

Ming Zhang ${ }^{1}$, Yudong Zhang ${ }^{2}$, Li Liư ${ }^{2}$ Lijuan Yu², Shirley Tsang ${ }^{3}$, Jing Tan², Wenhua Yao ${ }^{2}$, Manjit S Kang ${ }^{4}$, Yongqiang $\mathrm{An}^{5}$, Xingming Fan ${ }^{2^{*}}$

\begin{abstract}
Background: In the last decade, a large amount of microarray gene expression data has been accumulated in public repositories. Integrating and analyzing high-throughput gene expression data have become key activities for exploring gene functions, gene networks and biological pathways. Effectively utilizing these invaluable microarray data remains challenging due to a lack of powerful tools to integrate large-scale gene-expression information across diverse experiments and to search and visualize a large number of gene-expression data points.

Results: Gene Expression Browser is a microarray data integration, management and processing system with webbased search and visualization functions. An innovative method has been developed to define a treatment over a control for every microarray experiment to standardize and make microarray data from different experiments homogeneous. In the browser, data are pre-processed offline and the resulting data points are visualized online with a 2-layer dynamic web display. Users can view all treatments over control that affect the expression of a selected gene via Gene View, and view all genes that change in a selected treatment over control via treatment over control View. Users can also check the changes of expression profiles of a set of either the treatments over control or genes via Slide View. In addition, the relationships between genes and treatments over control are computed according to gene expression ratio and are shown as co-responsive genes and co-regulation treatments over control.

Conclusion: Gene Expression Browser is composed of a set of software tools, including a data extraction tool, a microarray data-management system, a data-annotation tool, a microarray data-processing pipeline, and a data search \& visualization tool. The browser is deployed as a free public web service (http://www.ExpressionBrowser. com) that integrates 301 ATH1 gene microarray experiments from public data repositories (viz. the Gene Expression Omnibus repository at the National Center for Biotechnology Information and Nottingham Arabidopsis Stock Center). The set of Gene Expression Browser software tools can be easily applied to the large-scale expression data generated by other platforms and in other species.
\end{abstract}

\section{Background}

A microarray measures the expression of thousands of genes simultaneously. This experimental system has revolutionized biological research by enabling discovery of a large set of genes whose expression levels reflect a given cell type, treatment, disease or development stage. Since the advent of this technology more than a decade

\footnotetext{
* Correspondence: xingmingfan@vip.km169.net

${ }^{2}$ Institute of Food Crops, Yunnan Academy of Agricultural Sciences, Kunming 650205, Yunnan Province, China

Full list of author information is available at the end of the article
}

ago, a large amount of expression data has been accumulated on more than 100 species [1]. Several initiatives have been undertaken to develop microarray public data repositories and analysis tools for scientists to share and utilize these data [2]. The public data repositories, such as NASC, NCBI GEO [3], EBI ArrayExpress [4,5] and NIG CIBEX [6], have been collecting, annotating, storing and redistributing large amounts of microarray data from diverse experiments. For example, NCBI GEO (http://www.ncbi.nlm.nih.gov/geo/) has collected 366,965 samples from 14,304 experiments. These

\section{Biomed Central}


microarray data are invaluable resources for scientific research and discovery.

Effective utilization of these datasets has, however, been limited because of a shortage of suitable tools to integrate large-scale and diverse microarray datasets. In most common use case, a scientist performs an experiment-based analysis: he or she downloads microarray data and sample annotations corresponding to a single experiment, inputs the data into a microarray dataanalysis tool, such as GeneSpring [2], HDBStat! [7], or Bioconductor packages [2], etc., and carries out singleexperiment centered analysis. In another common use case (e.g. for many gene-centric studies), a scientist wants to know how the expression of a given gene changes under various experimental conditions. The latter case is critically important for discovering gene functions, validating biomarkers, and developing new drugs targeted to specific genes. To answer gene-centric questions, we must have a tool that can be used to integrate a large amount of data from different microarray experiments. Developing such a tool presents several challenges.

The first challenge is the heterogeneity of data collected from different microarray experiments. Different microarray experiments from different laboratories are usually designed independently for specific research purposes. Heterogeneity might come from differences in experimental designs, materials sampled, developmental stages, treatment levels (including controls), and so on. The second challenge is to develop an effective software tool to process such a large amount of data at an acceptable speed with currently available hardware resources (i.e., CPU, memory and network). The third challenge is related to the complexity of displaying or visualizing data in a software tool. Most software tools, when applied to large data sets, display items in an extended page or multiple display pages. Therefore, it is impossible for users to get an overall view of the data on a single page. It is also inefficient and inconvenient for users to scroll display pages to find interesting information from thousands of data items. Thus, it is important to design a data display interface that can show both an overall view of a large-scale dataset in its totality and a detailed view of individual data points.

Genevestigator [8] and GeneChaser [1] are two webbased gene expression visualization tools that have successfully integrated a large number of microarray datasets and facilitated gene-centric and crossexperiment gene-expression discoveries. Genevestigator defines experiment annotation categories as Tissues/ Organs, Developmental Stage, Environmental Factors (Stimulus) and Mutation. The expression data and the analysis results are organized according to these categories. The microarray experiments are discarded if they cannot be classified into one of the predefined categories. GeneChaser, on the other hand, automatically reannotates and analyzes GDS datasets from NCBI GEO. It segregates all experimental conditions (treatment levels) into groups and then performs group versus group comparisons. However, the display systems of both Genevestigator and GeneChaser are limited. These two tools display data with heatmap or bar graphics on a display page with extended dimension or in multiple display pages. Only a limited number of data points can be shown at a time. Users have to scroll down the page to find interesting data points from among hundreds or thousands of total experimental conditions.

The GEB, on the other hand, displays efficiently a large number of data points simultaneously. This has been achieved by developing a set of software tools of data extraction, data management, data annotation, data processing, and gene expression profile search \& visualization. This set of software tools can be applied to microarray data in both public and private data repositories. The current public GEB web service (http://www. ExpressionBrowser.com) integrates 301 ATH1 microarray experiments that were originally stored in the data repositories of NCBI and NASC [9]. Arabidopsis, as a model plant, is widely used in various microarray experiments and gene-network modeling [10-12]. The results and knowledge obtained from Arabidopsis studies can be used as a reference for corresponding research on other plants, especially field crops $[13,14]$.

\section{Implementation \\ Overall design of workflow}

The GEB workflow is shown in Figure 1. Microarray data can be downloaded from public data repositories with the data extraction tool. Alternatively, data owners may upload their data directly into GEB. The data extraction tool harvests raw data files, sample annotations, and experimental designs from data repositories into the GEB data-management system. Data curators use the web-based interfaces of the data-management system to create sample sets by combing all replicated samples in each treatment level into individual groups (i.e. sample sets). Then, the data curators define a T/C by selecting a treatment sample set and a control sample set. In the data-processing pipeline, the microarray data are normalized, and the $\log 2$ ratio of treatment-overcontrol (LOG2R) and its t-test $P$ value are calculated. The normalized intensities of each chip, average intensities of each sample set, LOG2Rs and $P$ values of each $\mathrm{T} / \mathrm{C}$ are loaded into the GEB database, from which the data can be queried via the web-based search \& visualization tool. 


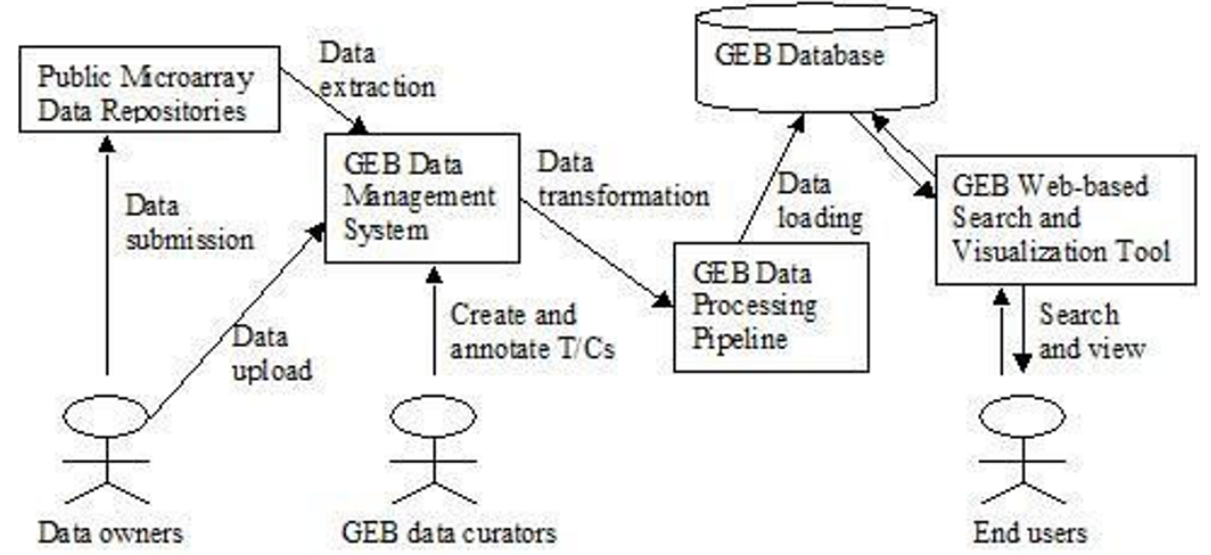

Figure 1 The schema and workflow of GEB. Microarray data can be downloaded into GEB from public repositories or uploaded into GEB by data owners. GEB is composed of a set of functional components. The major components are the data extractor (a command-line program), the data management system (a web application), the data processing pipeline (a set of command-line programs piped together), a MySQL database, and a web-based search and visualization tool.

\section{Affymetrix probe set annotation}

The probe sets on Affymetrix ATH1 chip were annotated via the following procedures: (1) Arabidopsis cDNA sequences and annotations were downloaded from TAIR (http://www.arabidopsis.org/) and ATH1 probe sequences were downloaded from Affymetrix; (2) All probe sequences were BLASTed against all cDNA sequences; (3) A probe set was mapped to a cDNA when nine or more probes in the probe set had a $100 \%$ match to a cDNA sequence (each $A T H 1$ probe set contains 11 probes); and (4) The annotation of matched cDNA was used as the annotation of the probe set.

\section{Data extraction and management}

The data extraction tool was developed using Java with Jakarta Commons Net Library (http://commons.apache. org/net/). The tool is a web crawler that recursively harvests raw data (such as Affymetrix CEL files), sample annotations, and experiment design descriptions from a repository website and then loads them into GEB database. To download data from different repositories, a corresponding plug-in component was developed for each repository. So far, two data extraction plug-ins have been developed for harvesting data from GEO and NASC.

The data-management system was developed for data curators to view and annotate the microarray data extracted from data repositories or submitted by data owners. Data curators annotate the data via the following steps:

First, a data curator creates a sample set by grouping replicated samples from every treatment level. The user interface for defining a sample set is shown in Figure 2A. A sample set name of "Wildtype_no treatment" is given at Name box and two replicates of "Wildtype_no treatment_Rep1" and "Widetype_no treatment_Rep2" are assigned to the sample set by moving them from the left panel to the right panel. Other sample sets in the experiment are created via the same procedure as noted above.

Second, a data curator creates a $\mathrm{T} / \mathrm{C}$ pair by choosing a treatment sample set and the corresponding control sample set from a drop-down menu (Figure 2B). For instance, we selected "ice1_no treatment" as treatment and "Wildtype_no treatment" as control to form a T/C. Then, the curator specifies a name of "ICE1 mutant vs. wild type" at Name box and detailed T/C information is given in Description box at the lower panel of Figure $2 \mathrm{~B}$. The control sample set is selected for a given treatment sample set so that only one-factor differs between the treatment and the control. Therefore, the biological effect of the $\mathrm{T} / \mathrm{C}$ will be clearly distinguished by the differential factor. All possible $\mathrm{T} / \mathrm{C}$ pairs were created in this way. In the example shown in Figure 2, a total of $10 \mathrm{~T} / \mathrm{Cs}$ are defined as follows: $3 \mathrm{~T} / \mathrm{Cs}$ for cold effects in a mutant (viz. "Ice1 mutant with cold treatment for $3 \mathrm{hr}$ vs. Ice1 mutant with no treatment", "Ice1 mutant with cold treatment for $6 \mathrm{hr}$ vs. Ice1 mutant with no treatment", and "Ice1 mutant with cold treatment for 24 hr vs. Ice1 mutant with no treatment"); $3 \mathrm{~T} / \mathrm{Cs}$ for cold effects in wild type (viz. "Wildtype with cold treatment for $3 \mathrm{hr}$ vs. Wildtype with no treatment", "Wildtype with cold treatment for $6 \mathrm{hr}$ vs. Wildtype with no treatment", and "Wildtype with cold treatment for $24 \mathrm{hr}$ vs. Wildtype with no treatment"); 3 T/Cs for mutation effects under cold treatment (viz. "Ice1 mutant with cold treatment for $3 \mathrm{hr}$ vs. Wildtype with cold treatment for $3 \mathrm{hr}$ ", "Ice1 mutant with cold treatment for $6 \mathrm{hr}$ vs. 


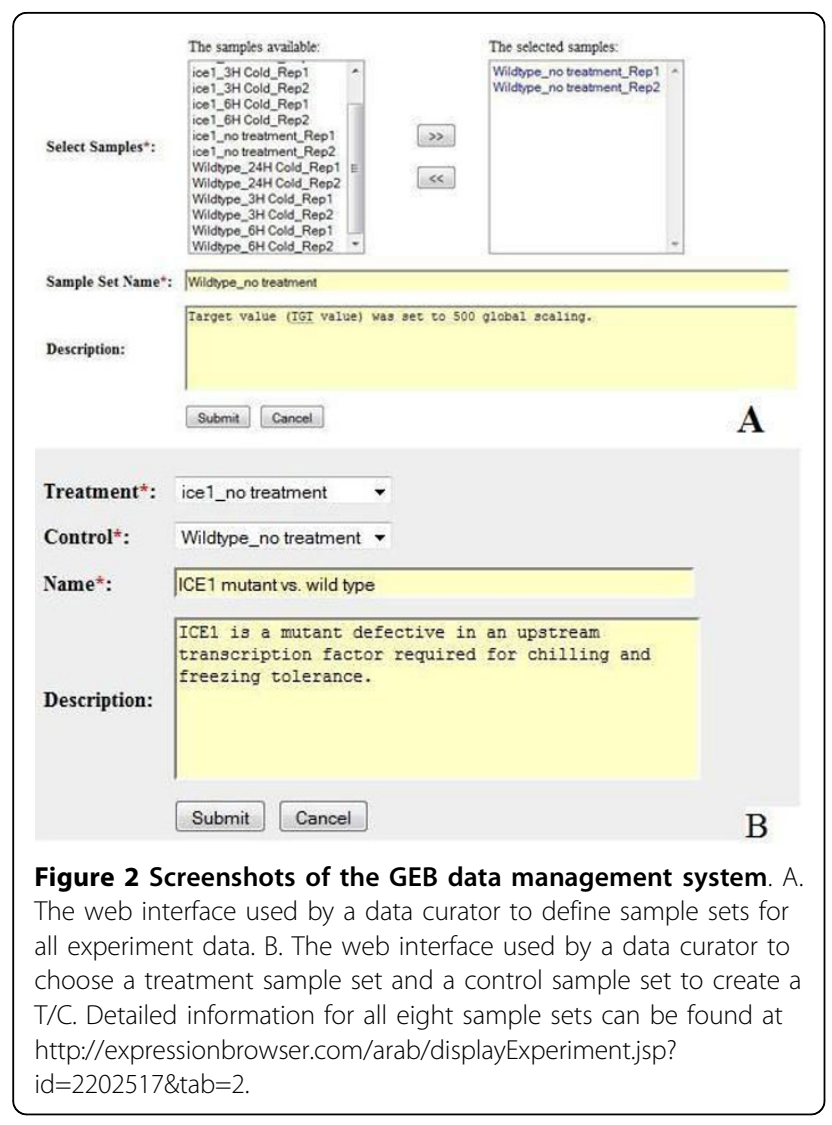

Wildtype with cold treatment for $6 \mathrm{hr}$ ", and "Ice1 mutant with cold treatment for $24 \mathrm{hr}$ vs. Wildtype with cold treatment for $24 \mathrm{hr}$ ); and one T/C for mutation effects without cold treatment (viz. "Ice1 mutant with no treatment vs. Wildtype with no treatment"). All 10 $\mathrm{T} / \mathrm{Cs}$ are shown at http://expressionbrowser.com/arab/ displayExperiment.jsp?id $=2202517 \& \operatorname{tab}=1$. After all treatment levels in each experiment are transformed into $\mathrm{T} / \mathrm{Cs}$, different experiments have same data structure and are comparable to one another and are, thus, easily integrated together. As a result, the heterogeneity caused by the differences in experimental designs is removed. The LOG2R of T/C also removes system errors that affect both treatment and control. Therefore, the ratio data generated based on $\mathrm{T} / \mathrm{Cs}$ can be more instructive and reliable than intensity data generated from treatment levels.

\section{Data processing and data quality monitoring}

The GEB data-processing pipeline is composed of four consecutive programs. The first program is for data normalization using the Robust Multichip Average (RMA) algorithm [15] that was implemented in the Bioconductor Affy package (http://www.bioconductor.org/ packages/2.4/bioc/html/affy.html). The second program takes this normalized intensity data as input and computes average intensities, standard deviations, LOG2Rs, and $P$ values of two-sample, two-tailed t-tests. The third program renders JPEG images of MA plots $[16,17]$ with average intensity as the $\mathrm{x}$-axis, LOG2R as the $\mathrm{y}$-axis, and $P$ value as the color. The images are loaded into the GEB application server (Tomcat) for data display when queried by users. The fourth program computes the mean percentage coefficient of variation $(\% \mathrm{CV})$ of all microarray features (genes) in a sample set using the following two steps. First, the standard deviation, mean, and \%CV of each feature (gene) in a sample set are calculated: that is, $\% \mathrm{CV}=100 *$ (Mean intensity/Standard deviation). Second, the mean \%CV of all features in the sample set is calculated. The mean \%CV of each of individual sample set is computed via the above procedure; the distribution of all mean \%CVs is shown in Figure 3. Most sample sets have mean \%CV between 0.5 and 4.68. There is a long tail to the right side of the distribution, in which the mean \%CV ranges from 4.68 to 16 . This result indicates that about $10 \%$ of the total sample sets have extremely large mean $\% \mathrm{CV}$, and thus probably have poor data quality. Mean $\% \mathrm{CV}$ of a sample set could be used to monitor quality of the sample set because higher mean \%CV implies larger variation among the replicated samples in the sample set. Therefore, any finding or conclusion from a sample set with high mean \%CV must be interpreted cautiously. We plan to filter out the sample sets with extremely high mean $\% \mathrm{CV}$ in the future to guarantee the quality of all the data in GEB.

Some microarray experiments in NASC or GEO were discarded because there were no replicated samples or no suitable controls. As of now, there are a total of 301 experiments, $1450 \mathrm{~T} / \mathrm{Cs}$, and 33,074,500 LOG2R data points in the Arabidopsis GEB database. Additional data, when available, can be easily entered into GEB.

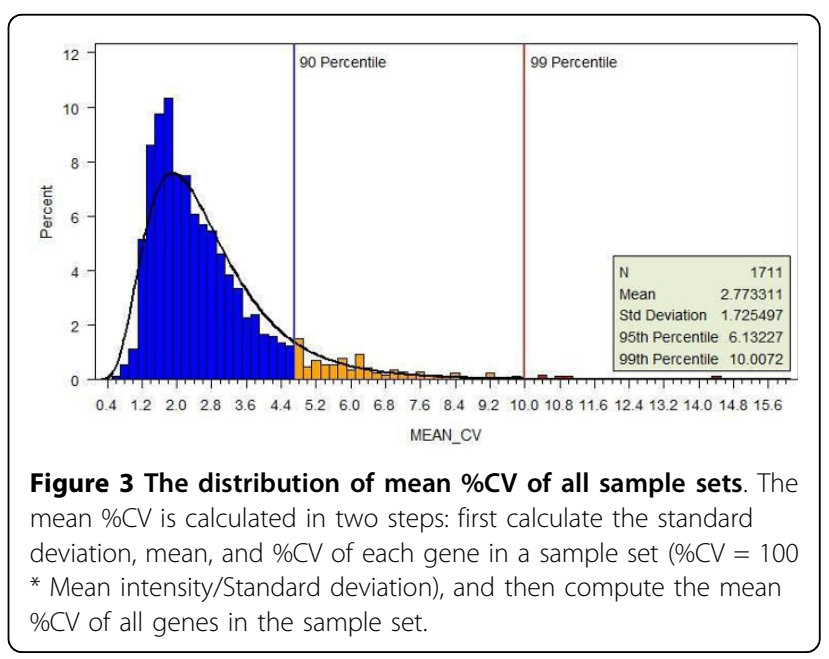




\section{Data search and visualization}

The Lucene search engine (http://lucene.apache.org/) is used for full-text search. Search index files in GEB are built with the text from gene identifiers, gene symbols, gene annotations, $\mathrm{T} / \mathrm{C}$ names, $\mathrm{T} / \mathrm{C}$ descriptions, experiment titles, and experiment descriptions. Genes, T/Cs, and experiments are searchable by matching keywords in the index files.

A 2-layer visualization display is designed to show large-scale data points as both an overall view and a detailed view. This visualization was developed using AJAX technology [18]. The first display layer is a static display (image) generated offline that contains all data points. The second layer is a real-time interactive display built by Web2.0 technology (JavaScript/AJAX). With the 2-layer display, users not only obtain an overall expression profile of the distribution of data points on the static plot, but can also get detailed information on each data point by real-time interactive searching or highlighting. The $P$ value of ratio data is shown by the color of the data. Therefore, data significance level is displayed at the same time as the magnitude of the data is.

\section{Results and Discussion}

\section{Full-text search}

With full-text searching, users can easily access the information inside GEB. The full text searching method employed by GEB is different from the searching in Genevestigator [8] or GeneChaser [1], in which only gene identifiers or symbols can be used for searching. Users can obtain expression information from Genevestigator or GeneChaser only when they clearly know the gene names or symbols. In contrast, GEB carries out full-text search for any word or letters for a gene symbol, gene annotation, $\mathrm{T} / \mathrm{C}$ name, T/C description, experiment title and experiment description. Users can freely explore the expression data with any search term they wish.

The full-text search is implemented in three places. The first is the GEB home page (http://www.ExpressionBrowser.com), where the user can enter keywords and find three types of information: genes, T/Cs and experiments. The second place is in Gene View (Figure 4), where users can search $\mathrm{T} / \mathrm{Cs}$ and investigate how different $\mathrm{T} / \mathrm{Cs}$ affect the expression of the selected gene. The third place is in the T/C View (Figure 5), where users can search genes and observe how the expressions of these genes are changed by the selected T/C.

\section{Gene View and co-responsive genes}

The GEB backend data model is a matrix with two dimensions, genes and T/Cs. Users visualize the expression profiles as a slice along either of these two dimensions: the Gene View displays data points of all $\mathrm{T} / \mathrm{Cs}$ for a selected gene, whereas the $\mathrm{T} / \mathrm{C}$ View displays data points of all genes for a selected $\mathrm{T} / \mathrm{C}$.

Figure 4 illustrates the Gene View. Data points from all $\mathrm{T} / \mathrm{Cs}$ for a gene are displayed in the MA plot $[16,17]$. Here, $M$, the $y$-axis, is the log2 ratio of treatment over

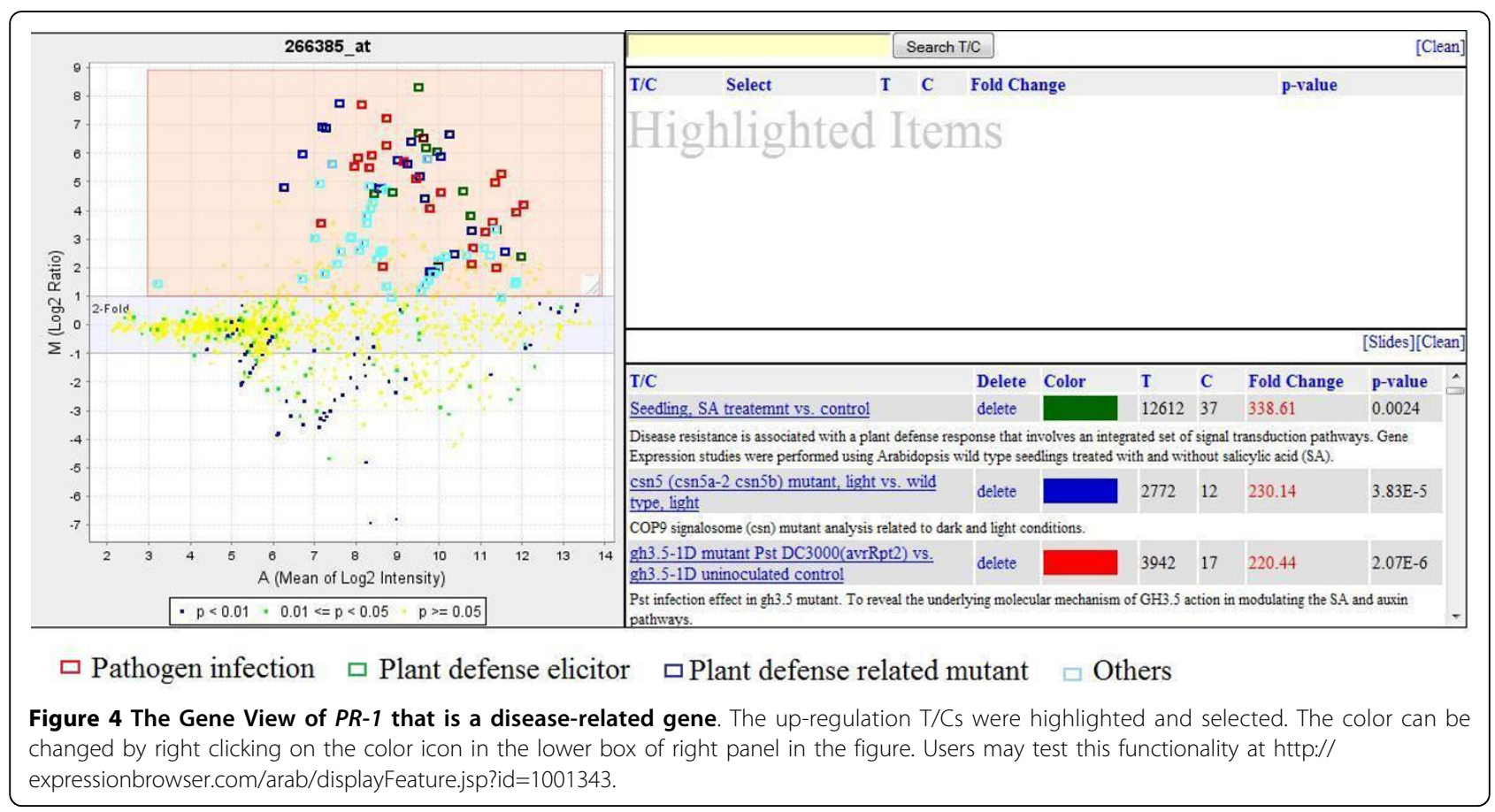




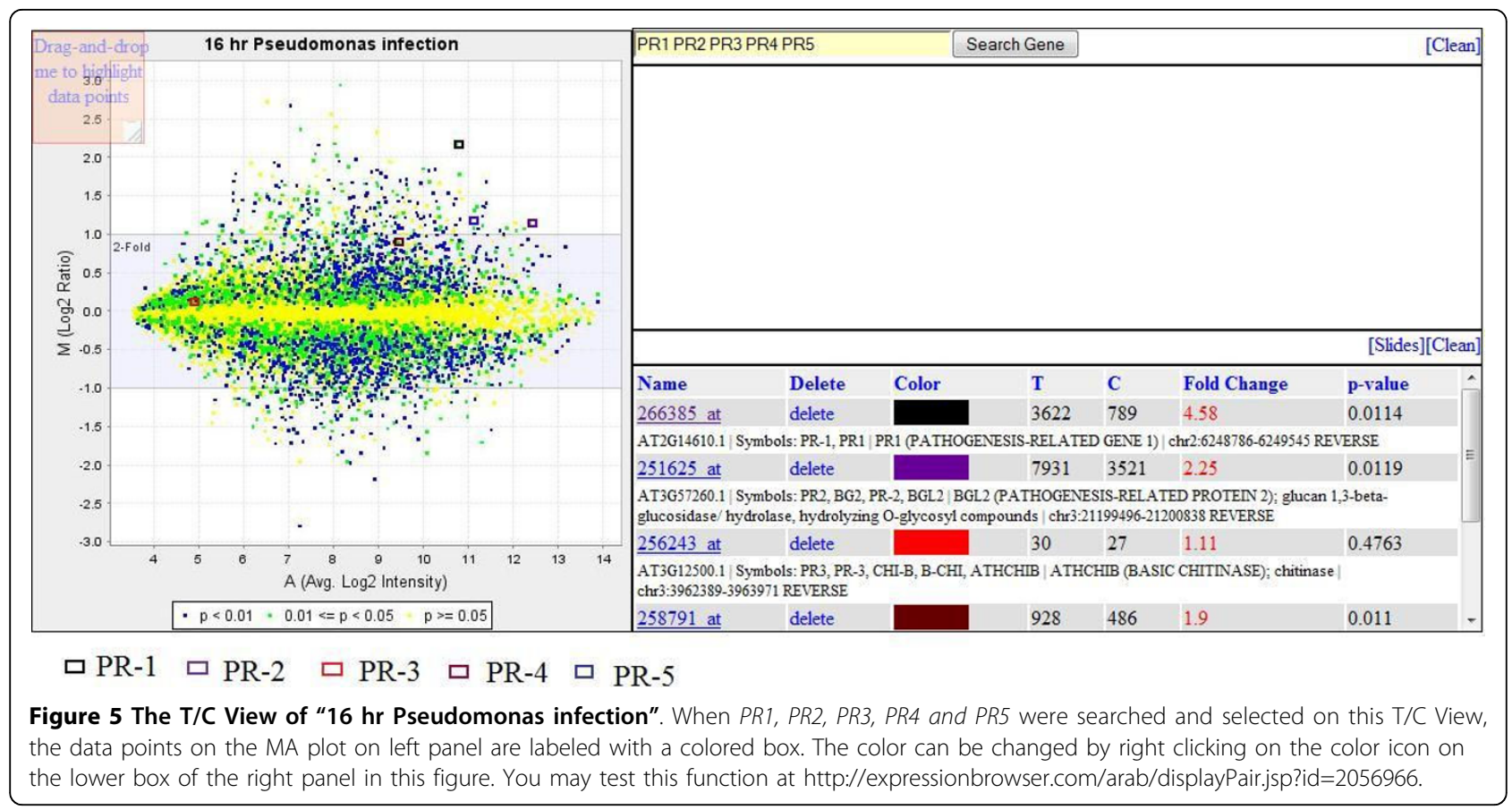

control (LOG2R) $[\log 2$ (treatment intensity) - $\log 2$ (control intensity)] and $\mathrm{A}$, the $\mathrm{x}$-axis, is the average $\log 2$ intensity of the treatment and control [ $(\log 2$ (treatment intensity) $+\log 2$ (control intensity))/2]. The MA plot provides a quick overview of data points for all $\mathrm{T} / \mathrm{Cs}$ affecting the selected gene. The data points located in the upper area of the MA plot are 'up-regulation' T/Cs, and those located at lower area are 'down-regulation' $\mathrm{T} /$ Cs. Gene View is a cross-experimental display of the expressions of a gene under all experimental conditions currently available in GEB. With the MA plot, users can get a clear overall view of a gene-expression profile without scrolling down the display page, no matter how many data points might be on the plot.

From a GEB MA plot, users can easily view both the LOG2R changes and also the statistical significance of the LOG2R. Each data point is color coded on the basis of the t-test $P$ value that indicates the significance level of its LOG2R. The data points are coded in blue color when $P$ values are lower than 0.01 , in green color when $P$ values are between 0.01 and 0.05 , and in yellow color when $P$ values are higher than 0.05 . The color-coded data points help users know visually significance levels and reliability of the data. For example, if the data point has both a high-fold change (at the top or bottom of the display) and high $P$ values $(P>$ 0.05 , yellow color), it suggests that there may be large systematic or experimental errors among replications so that the results should be interpreted cautiously before conclusion are drawn based on such a data point. Therefore, the location and color of the data points on the GEB MA plot give users a clear view of gene expression in both ratio scale and significance level (reliability).

The MA plot is a JPEG image generated by the offline data-processing pipeline. The image is about $60 \mathrm{~K}$ in size, with $480 \times 480$ pixel dimensions, which allows the image to be loaded from host server to users' browser very quickly so that users can rapidly obtain an overall view of the expression profile of a gene. Most importantly, GEB is equipped with highlighting and search functions that allow users to highlight data points by dragging-and-dropping the mouse and to search data by entering keywords. Figure 4 illustrates how to use the "highlighting window" to locate the up-regulation T/Cs on the MA plot. First, users move the "highlighting window" to cover the data points on the upper panel of the MA plot. The users can resize the window, if needed. The two text boxes to the right of the MA plot are used for listing detailed information about the highlighted data points. Users can click the 'Select' button for any $\mathrm{T} / \mathrm{C}$ on the upper text box and then the selected $\mathrm{T} / \mathrm{C}$ will be moved to lower text box. At the same time, the selected $\mathrm{T} / \mathrm{C}$ is also marked on the MA plot with a small rectangle. This two-layer display solution achieves both a quick overview of an expression profile and a detailed view of the selected data points.

Arabidopsis PR-1 gene, a pathogenesis-related gene [19], was used as an example of Gene View in Figure 4. The up-regulation $\mathrm{T} / \mathrm{Cs}$ selected in Figure 4 are listed in Table 1. A total of $95 \mathrm{~T} / \mathrm{Cs}$ were selected when 2fold and $\mathrm{P}<0.05$ were used as a double cutoff. Among 
Table $1 \mathrm{~A}$ list of T/Cs that induces the expression of the Arabidopsis PR-1 gene

\begin{tabular}{|c|c|c|c|}
\hline T/C Name & Treatment type & Fold Change & P-value \\
\hline Seedling, SA treatment vs. control & Plant defense elicitor & 338.61 & 0.0024 \\
\hline Csn5 (csn5a-2 csn5b) mutant, light vs. wild type, light & Plant defense related mutant & 230.14 & $3.83 \mathrm{E}-05$ \\
\hline gh3.5-1D mutant Pst DC3000(avrRpt2) vs. gh3.5-1D un-inoculated control & Pathogen infection & 220.44 & $2.07 \mathrm{E}-06$ \\
\hline Leaf, eds 16 mutant, Golovinomyces orontii infection for $7 \mathrm{~d}$ vs. eds 16 mutant, $0 \mathrm{~d}$ control & Pathogen infection & 160.28 & $2.21 \mathrm{E}-05$ \\
\hline Csn4-1 mutant, light vs. wild type, light & Plant defense related mutant & 130.35 & $6.81 \mathrm{E}-04$ \\
\hline Csn4-1 mutant vs. wild type & Plant defense related mutant & 125.67 & 0.0011 \\
\hline BTH Effect for $24 \mathrm{hr}$ in wrky 18 mutant & Plant defense elicitor & 111.62 & 0.0012 \\
\hline Whole plant, $m k k 1 / m k k 2$ vs. WT & Plant defense elicitor & 108.59 & $5.48 \mathrm{E}-04$ \\
\hline senescence effects in pod & Senescence & 97.64 & $2.67 \mathrm{E}-05$ \\
\hline cpr5scv1 double mutant & Plant defense related mutant & 88.61 & 0.0385 \\
\hline Pst DC3000 infection (12 hr) in WT & Pathogen infection & 83.37 & 0.0181 \\
\hline BTH Effect for $24 \mathrm{hr}$ in WT & Plant defense elicitor & 77.47 & 0.012 \\
\hline Whole plant, WT, 24 h BTH vs. WT control & Plant defense elicitor & 71.71 & 3.44E-07 \\
\hline Csn3-1 mutant, light vs. wild type, light & Plant defense related mutant & 67.19 & $7.58 \mathrm{E}-05$ \\
\hline 120 hr Erysiphe orontii infection & Pathogen infection & 64.8 & 0.0053 \\
\hline Whole plant, $m k k 2,24$ h BTH vs. $m k k 2$ control & Plant defense elicitor & 63.45 & 0.0042 \\
\hline Col-0 WT, Pst DC3000 (avrRpt2) infection vs. un-inoculated control & Pathogen infection & 60.32 & 0.0182 \\
\hline Cold 7 days effects & Others & 58.93 & 0.0061 \\
\hline cpr5 mutant & Plant defense related mutant & 56.63 & 0.0354 \\
\hline Pst DC3000 infection (12 hr) in wrky17 mutant & Pathogen infection & 55.62 & 0.0293 \\
\hline siz1-3 mutant drought with treatment vs. Col-0 WT with drought treatment & Plant defense related mutant & 52.98 & 0.0034 \\
\hline Brm-101 mutant vs. Ler WT & Others & 52.5 & 0.0221 \\
\hline 96 hr Erysiphe orontii infection & Pathogen infection & 49.32 & $2.50 \mathrm{E}-05$ \\
\hline Phytophthora infection for $24 \mathrm{hr}$ & Pathogen infection & 47.65 & $3.19 \mathrm{E}-05$ \\
\hline 32 hr PsES4326 infection vs 9 hr PsES4326 infection & Pathogen infection & 41.11 & 0.0267 \\
\hline siz1-3 mutant vs. Col-0 WT & Plant defense related mutant & 38.88 & 0.0031 \\
\hline Pst DC3000 infection (12 hr) in wrky11 mutant & Pathogen infection & 37.07 & 0.0093 \\
\hline 24 hr PsES4326 infection vs 9 hr PsES4326 infection & Pathogen infection & 33.64 & 0.0297 \\
\hline E2Fa-DPa over-expressing & Others & 32.75 & 0.009 \\
\hline Cotyledon & Others & 30.2 & $8.69 \mathrm{E}-05$ \\
\hline Chitin receptor mutant, chitooctaose treatment vs. Wild type, chitooctaose treatment & Plant defense elicitor & 29.64 & 7.04E-04 \\
\hline shoot vs root & Others & 29.61 & $8.02 \mathrm{E}-04$ \\
\hline $\operatorname{csn} 5(\operatorname{csn} 5 a-2 \operatorname{csn} 5 b)$ mutant, dark vs. wild type, dark & Plant defense related mutant & 29.26 & 0.007 \\
\hline Chitin receptor mutant vs. Wild type & Plant defense related mutant & 28.92 & $3.09 \mathrm{E}-05$ \\
\hline flower stage 15 , sepals & Others & 28.05 & $1.08 \mathrm{E}-04$ \\
\hline Whole plant, mkk1, 24 h BTH vs. mkk1 control & Plant defense elicitor & 26.74 & 0.0174 \\
\hline Leaf, WT, Golovinomyces orontii infection for $7 \mathrm{~d}$ vs. $0 \mathrm{~d}$ control & Pathogen infection & 26.06 & $2.36 \mathrm{E}-07$ \\
\hline BTH Effect for $8 \mathrm{hr}$ in WT & Plant defense elicitor & 26.06 & 0.0201 \\
\hline BTH Effect for 8 hr in wrky 18 mutant & Plant defense elicitor & 25.92 & $3.30 \mathrm{E}-04$ \\
\hline camta3-2 mutant vs. wild type & Plant defense related mutant & 22.87 & 0.0358 \\
\hline cdpk6-yfp 4 transgene effects & Others & 20.98 & 0.0151 \\
\hline PsmES4326 infection for $32 \mathrm{hr}$ & Pathogen infection & 19.53 & 0.0079 \\
\hline Leaf, WT, Golovinomyces orontii infection for $5 \mathrm{~d}$ vs. $0 \mathrm{~d}$ control & Pathogen infection & 17.73 & $2.80 \mathrm{E}-06$ \\
\hline S15-118 mutant vs. WT & Others & 17.6 & 0.0368 \\
\hline PsmES4326 infection for $24 \mathrm{hr}$ & Pathogen infection & 16.37 & 0.0072 \\
\hline flower stage 15 & Others & 14.82 & $1.09 \mathrm{E}-04$ \\
\hline BTH treatment in WT vs. WT control & Plant defense elicitor & 14.78 & $3.70 \mathrm{E}-04$ \\
\hline
\end{tabular}




\section{Table 1 A list of T/Cs that induces the expression of the Arabidopsis PR-1 gene (Continued)}

\begin{tabular}{|c|c|c|c|}
\hline Pseudomonas syringae pv phaseolicola infiltration for $24 \mathrm{hr}$ & Pathogen infection & 12.87 & 0.0015 \\
\hline mature leaves, 35 days after sowing vs. Average & Others & 12.58 & 0.0232 \\
\hline 72 hr Erysiphe orontii infection & Pathogen infection & 12.55 & 0.0086 \\
\hline old rosette leaf vs young rosettet leaf in WT & Senescence & 10.82 & 0.0235 \\
\hline SPH1 knockout vs WT in young rosette leaf & Others & 10.69 & 0.0187 \\
\hline pmr5 pmr6 double mutant vs. WT & Plant defense related mutant & 10.46 & 0.0293 \\
\hline Pseudomonas syringae pv tomato avrRpm1 infiltration for $24 \mathrm{hr}$ & Pathogen infection & 10.19 & 0.0036 \\
\hline flower stage 12 equivalent ( 7 ) & Others & 8.83 & $3.61 \mathrm{E}-04$ \\
\hline sni1 mutant & Others & 8.59 & 0.0117 \\
\hline flower stage 12 equivalent (6) & Others & 8.58 & $2.48 \mathrm{E}-04$ \\
\hline High nitrogen and glucose effects & Others & 7.64 & 0.0015 \\
\hline Pnp1-1, phosphate deficiency 1 wk vs. WT, phostphate deficiency 1 wk & Others & 6.92 & 0.0259 \\
\hline Pseudomonas syringae pv tomato DC3000 hrcC-infiltration for $24 \mathrm{hr}$ & Pathogen infection & 6.78 & $1.75 E-04$ \\
\hline glucose effects & Others & 6.42 & $7.38 \mathrm{E}-04$ \\
\hline Pnp1-1, phosphate efficiency 1 wk vs. WT, phostphate efficiency 1 wk & Others & 6.36 & 0.0173 \\
\hline mil4 overexpression line with BTH treatment vs. mil4 overexpression line control & Plant defense elicitor & 6.3 & $5.77 \mathrm{E}-04$ \\
\hline flower stage 12 , sepals & Others & 6.2 & $3.95 \mathrm{E}-04$ \\
\hline arr10 arr12 double null mutant effects under cytokinin & Others & 6.03 & 0.0034 \\
\hline pmr5 mutant vs. WT & Plant defense related mutant & 5.88 & 0.0412 \\
\hline WT, INA $48 \mathrm{~h}$ vs. control $48 \mathrm{~h}$ & Others & 5.77 & 0.0437 \\
\hline pnp1-1 mutant, phosphate starvation for 1 wk vs. pnp1-1 mutant, 1 wk control & Others & 5.74 & 0.0402 \\
\hline BTH treatment in mil4 mutant vs. $\mathrm{H} 2 \mathrm{O}$ in mil4 mutant & Plant defense elicitor & 5.52 & 0.0028 \\
\hline Cotyledon & Others & 5.46 & $3.86 \mathrm{E}-04$ \\
\hline WT, phosphate starvation for 1 wk vs. 1 wk control & Others & 5.28 & 0.0166 \\
\hline seedling 3 vs average & Others & 5.1 & $8.30 \mathrm{E}-04$ \\
\hline seedling 2 vs average & Others & 4.87 & 0.001 \\
\hline SAM SE, 35S:AGL15 VS. WT & Others & 4.64 & 0.0461 \\
\hline 16 hr Pseudomonas infection & Pathogen infection & 4.58 & 0.0114 \\
\hline gl1T rosette leaf $\# 4,1 \mathrm{~cm}$ long & Others & 4.53 & $1.56 \mathrm{E}-04$ \\
\hline Pseudomonas syringae pv phaseolicola infiltration for $6 \mathrm{hr}$ & Pathogen infection & 4.33 & 0.0308 \\
\hline senescing leaves & Senescence & 4.32 & $3.95 \mathrm{E}-05$ \\
\hline Botrytis cinerea infection on 48 hpi leaf & Pathogen infection & 4.17 & 0.0247 \\
\hline Col-0 rosette leaf \#4 & Others & 4.08 & 0.0016 \\
\hline mil4 mutant vs. WT & Plant defense related mutant & 3.81 & 0.0031 \\
\hline gl1T rosette leaf \#12 & Others & 3.64 & $3.24 \mathrm{E}-04$ \\
\hline flower stage 12 equivalent (5) & Others & 3.62 & 0.0028 \\
\hline$\overline{\text { Leaf }}$ & Others & 3.22 & 0.0016 \\
\hline cauline leaves & Others & 3.13 & 0.0023 \\
\hline shoot under potassium starvation & Others & 3 & 0.0098 \\
\hline Met1-3 mutant leaf (4th generation) vs. Col-0 WT & Others & 2.9 & 0.0353 \\
\hline shoot under Caesium treatment & Others & 2.9 & 0.0061 \\
\hline Col-0 rosette leaf \#4 & Others & 2.76 & 0.0018 \\
\hline $24 \mathrm{hr}$ control vs $0 \mathrm{hr}$ control & Others & 2.7 & 0.0158 \\
\hline Ambient $\mathrm{CO} 2$ and Ambient Light at $96 \mathrm{hr}$ vs $0 \mathrm{hr}$ & Others & 2.49 & 0.0364 \\
\hline rosette leaf \# 2 & Others & 2.45 & 0.0075 \\
\hline leaf 7, distal half & Others & 2.42 & 0.0023 \\
\hline HSP90 reduced mutant (RNAi-B1) vs. Control-3 & Others & 2.05 & 0.0063 \\
\hline gh3.5-1D mutant, Pst DC3000 (avrRpt2) infection vs. Col-0 WT, Pst DC3000 (avrRpt2) infection & Others & 2.03 & 0.0263 \\
\hline
\end{tabular}


the $95 \mathrm{~T} / \mathrm{Cs}, 44 \mathrm{~T} / \mathrm{Cs}$ are pathogen treatments, $13 \mathrm{~T} / \mathrm{Cs}$ are plant defense elicitor treatments, and $14 \mathrm{~T} / \mathrm{Cs}$ are plant defense-related mutants. These results clearly suggested that the expression of $P R-1$ was promoted by infections, plant-defense elicitors, and plant defenserelated mutations. In previous studies, $P R-1$ was defined as a pathogenesis-related gene that was coordinately activated by pathogen infection and functioned as an indicator of the defense reaction [20,21]. The silencing of this gene leads to an increase in extracellular $\beta$ $(1 \rightarrow 3)$-glucanase activity at the onset of tobacco defense reactions [22-24]. A decrease in $\beta-(1 \rightarrow 3)$-glucan deposition in $P R-1$-silenced lines [22] might cause less deposition of callose that is linked with $\beta-(1 \rightarrow 3)$-glucan and while the callose deposition is one of the characteristics of defense reactions associated with hypersensitive response of a plant [25]. Morris et al. [26] indicated that chemical induction of maize $P R-1$ genes increased resistance to downy mildew. The results for $P R-1$ functions revealed by GEB were impressively consistent with the previous findings. These results strongly suggested that Gene View of GEB would be very useful in genefunction discovery, biomarker validation, and bioprocess identification.

Figure 6 represents a screenshot of "Co-responsive Genes" tab in the PR-1 Gene View (http://www. expressionbrowser.com/arab/displayFeature.jsp?id= $1001343 \&$ tab $=4$ ). The co-responsive relationship of two genes is determined by the following procedure: (1) The up- and down-regulation $\mathrm{T} / \mathrm{Cs}$ of the two genes are selected using a double cutoff of $P<0.05$ and of 2 -fold; (2) the overlap $\mathrm{T} / \mathrm{Cs}$ that have the two genes selected are then used to compute the overlap percentage; (3) the Pearson correlation coefficient is calculated using the LOG2R of overlapped T/Cs; and (4) a relationship index is calculated using the overlap percentage multiplied by the square of the correlation coefficient. The relationship between the two co-responsive genes is computed with ratio data from $\mathrm{T} / \mathrm{C}$ with only a single factor differing between treatment and control. Therefore, the relationship between co-responsive genes solely reflects the effect of a biological treatment because the variations caused by most other factors are removed. On the other hand, if the relationship between co-expressed genes is computed with intensity data where multiple factors vary (such as tissue and cell type of sample, biological treatment, sampling methods, such as time and location, experimental methods, such as sample storage, mRNA extraction, or microarray dying, and systematic errors), then the relationship between co-expression genes reflects the mixed effects from biological treatment and these multiple factors. In the list of $P R-1$ co-responsive genes (Figure 6), impressively, many well-known plant defense-related genes, such as EXLB3, PR-2, Chitinase, $P R-5$ and $A G P 5$, were found. Among them, $P R-2$ and

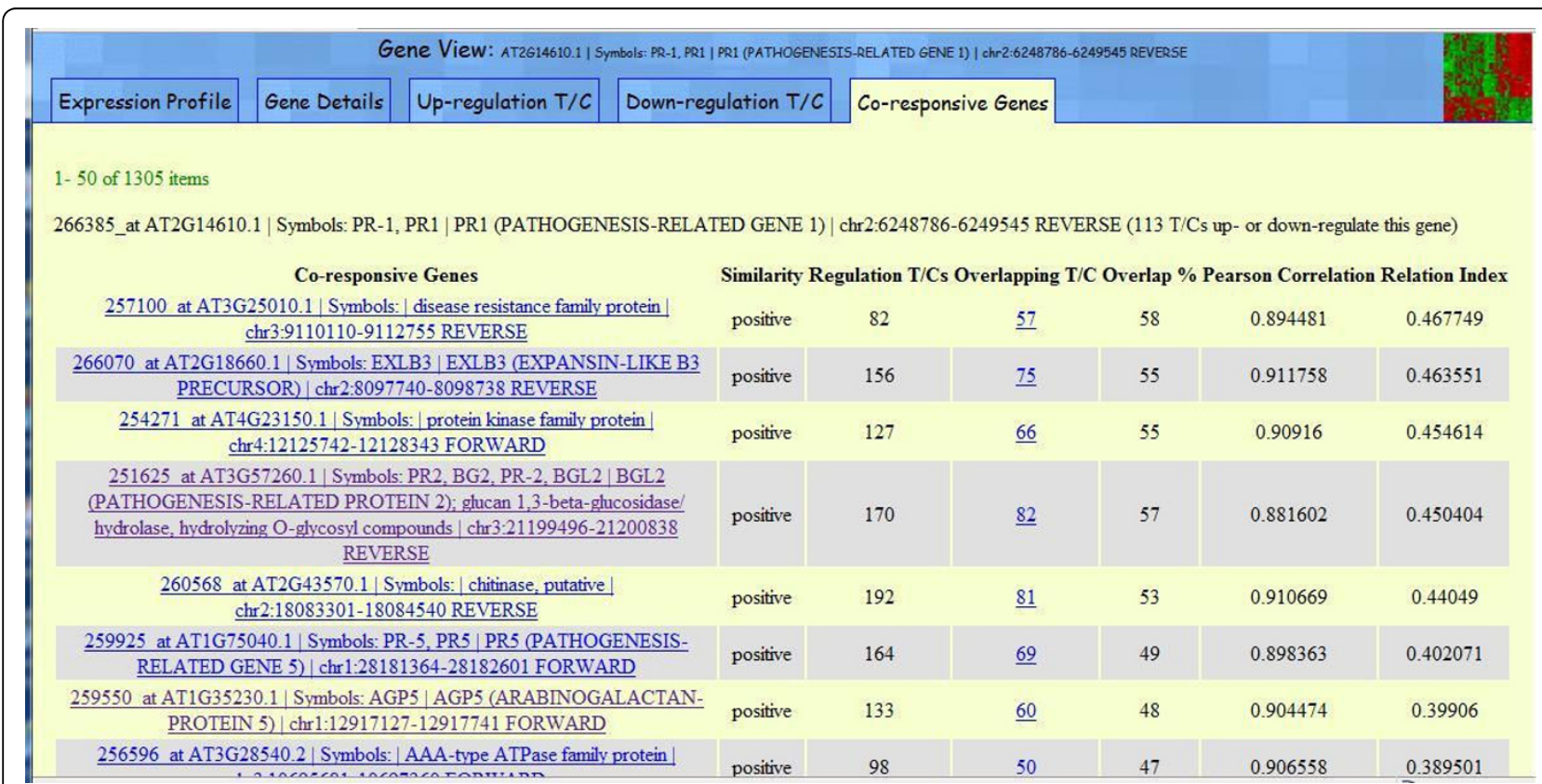

Figure 6 The co-responsive genes related to $\boldsymbol{P} \boldsymbol{R}-\mathbf{1}$. The co-responsive genes were listed in the order of their relation index to $P R-1$ genes. The relation index is a product of the overlap percentage (the percentage of overlapped co-regulation T/Cs between $P R-1$ and the selected gene) and the correlation coefficient (the Pearson correlation coefficient among the overlapped T/Cs). More co-regulation T/Cs can be found at http:// expressionbrowser.com/arab/displayFeature.jsp?id=1001343\&tab=4. 
$P R-5$ are considered to have a similar function as $P R-1$ in systemically acquired resistance (SAR) responses [27]. According to a review on the integrated application of online data mining tools by Meier and Gehring [28], $P R-1, P R-2$ and $P R-5$ were induced by necrotrophic Botrytis cinerea pathogen. The results shown by GEB are consistent with those from previous studies. The consensus results from multiple experiments in GEB provide reliable clues for gene-expression discoveries.

\section{T/C View and co-regulation T/Cs}

Figure 5 represents an example of T/C View of " $16 \mathrm{hr}$ Pseudomonas infection." Each data point on the T/C View is the LOG2R of a gene. The MA plot, color codes, two-layer display design, and searching/highlighting functions on the $\mathrm{T} / \mathrm{C}$ View are exactly the same as those in Gene View described above. The following example shows how to use search function to locate genes in the T/C View. When a string of "PR1 PR2 PR3 PR4 PR5" was used as a search keyword, all genes with any matching word in its annotation are shown in the upper right box (Figure 5). By clicking the 'Select' button on each gene, the gene is moved to the lower box. At the same time, the selected gene is marked on an MA plot with a small rectangle. $\mathrm{T} / \mathrm{C}$ view provides a condition-centric view of microarray data.

Though different T/Cs may stimulate different sets of genes, any two different T/Cs may co-regulate a set of genes such that they have similar gene-expression signatures. The co-regulation relationship between two $\mathrm{T} / \mathrm{Cs}$ can be constructed from the similarity of geneexpression signatures of the two T/Cs. If we click the "Co-regulation T/Cs" tab in the T/C View of "16 hr Pseudomonas infection" (http://expressionbrowser. com/arab/displayPair.jsp?id=2056966\&tab=4), a total of 199 co-regulation T/Cs are listed in a table ordered by their "relation index" to the " $16 \mathrm{hr}$ Pseudomonas infection" T/C. The calculation of relation index between the two $\mathrm{T} / \mathrm{Cs}$ is described in the footnote in Table 2. The T/C of "24 hr Pseudomonas infection" has the closest relationship (with relation index of 0.623816 ) to "16 hr Pseudomonas infection." This result is easily understood because they are the same treatment with an 8-hour treatment-time difference. The top 80 (of the 199) co-regulation T/Cs of " $16 \mathrm{hr}$ Pseudomonas infection" are listed in Table 2: 29 belong to pathogeninfection, 16 are plant-defense elicitors, and 6 are plant defense-related mutants. It is interesting to note that 3 $\mathrm{T} / \mathrm{Cs}$ are negatively correlated with the $\mathrm{T} / \mathrm{C}$ of " $16 \mathrm{hr}$ Pseudomonas infection" (Table 2). Two of the three T/ Cs are mutants of Enhanced Disease Susceptibility 16 (EDS16) under infection conditions. EDS genes have special function in basal disease resistance to pathogens as well as $R$ genes [29,30]. Arabidopsis EDS mutants, such as eds1 [31] and eds5 [32], have lower PR gene-expression level and exhibit higher susceptibility to pathogen infection. The reverse relationship of gene-expression signatures between EDS16 under infection and "16 hr Pseudomonas infection" implies that some pathogen-related genes are either not activated or reduced in EDS16 mutants when they are infected by pathogens. Another T/C negatively correlated with the "16 hr Pseudomonas infection" is caused by "high nitrogen effect". Hoffland et al. [33] reported that high nitrogen application caused higher $\mathrm{N}$ concentration in plant tissue, and the effect of tissue $\mathrm{N}$ concentration on disease susceptibility was highly pathogen-dependent. They found that disease susceptibility to P. syringae and Oidium lycopersicum was significantly increased with increasing $\mathrm{N}$ concentration in tomato tissue [34]. The results obtained from GEB are consistent with the previous independent studies, further suggesting that the results generated by GEB are reliable and the logic/principles implemented in GEB are scientifically sound.

Gene network building has been a hot research topic during the past few years $[10,12,34,35]$. GEB is not only able to construct gene networks based on the coresponsive relationship described above (Figure 6) but is also able to construct T/C networks based on the coregulation relationship (Table 2). Another paper will address the details about constructing gene networks and T/C networks in Arabidopsis.

\section{Slide View}

The slide view of genes or T/Cs is designed to help users discover changes in multiple genes under various $\mathrm{T} / \mathrm{Cs}$ or vice versa. Users can make a slide show to compare a set of T/Cs with multiple selected genes. For example, the user can search $\mathrm{T} / \mathrm{C}$ conditions in Gene View (Figure 4) by typing "cold" in the search box and then selecting three $\mathrm{T} / \mathrm{C}$ conditions with cold treatment of $12 \mathrm{hr}, 6 \mathrm{hr}$, and $3 \mathrm{hr}$ from the upper right box to the lower right box. After selecting the three "cold" conditions, the user can also search another three non-related T/Cs, such as "drought," "UV-B" and "wounding" with the same procedure. After the six necessary $\mathrm{T} / \mathrm{C}$ conditions are selected, the user can click the "[slide]" link and then the six MA plots of T/Cs are shown as slides (Figure 7). In Figure 7A, the user highlights a certain number of genes by dragging, dropping and resizing the "highlighting window." A total of 51 genes with at least 30-fold increase (LOG2R > 4.9) in 12-hr cold condition are selected. To see how the selected genes are changed in other T/Cs, click the "next slide" arrow, and the next slide will appear. The selected genes in the first slide are still highlighted but the positions of the selected genes 
Table 2 The co-regulation T/Cs with expression profiles correlated to the T/C of "16 hr Pseudomonas infection" (A) ${ }^{1}$

\begin{tabular}{|c|c|c|c|c|c|c|}
\hline T/C Name & Classification & $\begin{array}{c}\text { Gene } \\
\text { Number } \\
(B)^{2}\end{array}$ & $\begin{array}{c}\text { Overlapping } \\
\text { Gene } \\
\text { Number } \\
\text { (C) } \\
\end{array}$ & $\begin{array}{c}\text { Overlapping } \\
\text { Percentage } \\
\%(\mathrm{OP})^{4}\end{array}$ & $\begin{array}{l}\text { Correlation } \\
\text { Coefficient } \\
\text { (CC })^{5}\end{array}$ & $\begin{array}{c}\text { Relation } \\
\text { Index } \\
(\mathrm{RI})^{6}\end{array}$ \\
\hline $24 \mathrm{hr}$ Pseudomonas infection & Pathogen infection & 477 & 277 & 64 & 0.982917 & 0.623816 \\
\hline $\begin{array}{l}\text { Leaf, WT, Golovinomyces orontii infection for } 5 \mathrm{~d} \text { vs. } 0 \mathrm{~d} \\
\text { control }\end{array}$ & Pathogen infection & 716 & 241 & 43 & 0.93683 & 0.385622 \\
\hline BTH Effect for $8 \mathrm{hr}$ in wrky 18 mutant & $\begin{array}{l}\text { Plant defense } \\
\text { elicitor }\end{array}$ & 1245 & 296 & 36 & 0.943639 & 0.3242 \\
\hline BTH Effect for $8 \mathrm{hr}$ in WT & $\begin{array}{l}\text { Plant defense } \\
\text { elicitor }\end{array}$ & 1614 & 308 & 30 & 0.951557 & 0.279581 \\
\hline SA effect at $6 \mathrm{hr}(\mathrm{Col}-0)$ & $\begin{array}{l}\text { Plant defense } \\
\text { elicitor }\end{array}$ & 421 & 121 & 30 & 0.954483 & 0.274902 \\
\hline $\begin{array}{l}\text { Pseudomonas syringae pv tomato DC3000 hrcC-infiltration for } \\
24 \mathrm{hr}\end{array}$ & Pathogen infection & 1065 & 223 & 30 & 0.939357 & 0.272162 \\
\hline BTH treatment in mil4 mutant vs. $\mathrm{H} 2 \mathrm{O}$ in mil4 mutant & $\begin{array}{l}\text { Plant defense } \\
\text { elicitor }\end{array}$ & 652 & 184 & 35 & 0.872943 & 0.271469 \\
\hline BTH Effect for $24 \mathrm{hr}$ in wrky 18 mutant & $\begin{array}{l}\text { Plant defense } \\
\text { elicitor }\end{array}$ & 1655 & 307 & 30 & 0.935343 & 0.263835 \\
\hline $\begin{array}{l}\text { Leaf, eds 16, Golovinomyces orontii infection for } 5 \mathrm{~d} \text { vs. WT, } \\
\text { infection for } 5 \mathrm{~d}\end{array}$ & $\begin{array}{l}\text { Plant defense } \\
\text { related mutant }\end{array}$ & 495 & 169 & 38 & -0.82538 & 0.26286 \\
\hline siz1-3 mutant vs. Col-0 WT & $\begin{array}{l}\text { Plant defense } \\
\text { related mutant }\end{array}$ & 987 & 221 & 32 & 0.889254 & 0.255498 \\
\hline $\begin{array}{l}\text { mil4 overexpression line with BTH treatment vs. mil4 } \\
\text { overexpression line control }\end{array}$ & $\begin{array}{l}\text { Plant defense } \\
\text { elicitor }\end{array}$ & 574 & 181 & 37 & 0.820014 & 0.254887 \\
\hline SA effects at 4 hr (MT-0) & $\begin{array}{l}\text { Plant defense } \\
\text { elicitor }\end{array}$ & 702 & 158 & 29 & 0.934091 & 0.254588 \\
\hline BTH Effect for $24 \mathrm{hr}$ in WT & $\begin{array}{l}\text { Plant defense } \\
\text { elicitor }\end{array}$ & 2062 & 341 & 27 & 0.94732 & 0.250527 \\
\hline pmr5 pmr6 double mutant vs. WT & $\begin{array}{l}\text { Plant defense } \\
\text { related mutant }\end{array}$ & 423 & 126 & 31 & 0.892795 & 0.249832 \\
\hline $\begin{array}{l}\text { Leaf, WT, Golovinomyces orontii infection for } 7 \mathrm{~d} \text { vs. } 0 \mathrm{~d} \\
\text { control }\end{array}$ & Pathogen infection & 2111 & 329 & 26 & 0.940966 & 0.23379 \\
\hline BTH treatment in WT vs. WT control & $\begin{array}{l}\text { Plant defense } \\
\text { elicitor }\end{array}$ & 496 & 141 & 32 & 0.847156 & 0.230768 \\
\hline 120 hr Erysiphe orontii infection & Pathogen infection & 591 & 159 & 32 & 0.837777 & 0.229624 \\
\hline Whole plant, mkk2, 24 h BTH vs. mkk2 control & $\begin{array}{l}\text { Plant defense } \\
\text { elicitor }\end{array}$ & 973 & 225 & 33 & 0.828929 & 0.228364 \\
\hline SA effect at $4 \mathrm{hr}$ (Est) & $\begin{array}{l}\text { Plant defense } \\
\text { elicitor }\end{array}$ & 259 & 78 & 24 & 0.96622 & 0.22756 \\
\hline PsmES4326 infection for $9 \mathrm{hr}$ & Pathogen infection & 340 & 99 & 27 & 0.90638 & 0.225606 \\
\hline Phytophthora infection for $24 \mathrm{hr}$ & Pathogen infection & 776 & 152 & 26 & 0.919965 & 0.222373 \\
\hline Pseudomonas syringae pv phaseolicola infiltration for $24 \mathrm{hr}$ & Pathogen infection & 1667 & 256 & 25 & 0.93104 & 0.216709 \\
\hline upf3 mutant vs WT & Others & 635 & 123 & 24 & 0.938378 & 0.213205 \\
\hline Whole plant, WT, 24 h BTH vs. WT control & $\begin{array}{l}\text { Plant defense } \\
\text { elicitor }\end{array}$ & 707 & 165 & 30 & 0.834236 & 0.211088 \\
\hline Pst DC3118 COR-hrpS double mutant infection $10 \mathrm{hr}$ & Pathogen infection & 418 & 90 & 22 & 0.963317 & 0.209057 \\
\hline Ozone effects & $\begin{array}{l}\text { Plant defense } \\
\text { elicitor }\end{array}$ & 1544 & 247 & 25 & 0.898834 & 0.207327 \\
\hline SA effect at $4 \mathrm{hr}$ (Tsu-1) & $\begin{array}{l}\text { Plant defense } \\
\text { elicitor }\end{array}$ & 294 & 83 & 24 & 0.911413 & 0.204284 \\
\hline cpr5scv1 double mutant & $\begin{array}{l}\text { Plant defense } \\
\text { related mutant }\end{array}$ & 742 & 163 & 29 & 0.833698 & 0.20177 \\
\hline $\begin{array}{l}\text { Leaf, eds } 16 \text { mutant, Golovinomyces orontii infection for } 7 \mathrm{~d} \text { vs. } \\
\text { eds } 16 \text { mutant, } 0 \mathrm{~d} \text { control }\end{array}$ & Pathogen infection & 2644 & 341 & 22 & 0.939944 & 0.199188 \\
\hline Phytophthora infection for $12 \mathrm{hr}$ & Pathogen infection & 877 & 152 & 24 & 0.907767 & 0.199132 \\
\hline
\end{tabular}


Table 2 The co-regulation T/Cs with expression profiles correlated to the T/C of "16 hr Pseudomonas infection" (A) (Continued)

\begin{tabular}{|c|c|c|c|c|c|c|}
\hline shoot under Caesium treatment & Others & 187 & 64 & 22 & 0.938556 & 0.19851 \\
\hline E. coli TUV86-2 fliC mutant infection $7 \mathrm{hr}$ & Pathogen infection & 859 & 136 & 21 & 0.941937 & 0.194622 \\
\hline Whole plant, mkk1, 24 h BTH vs. mkk1 control & $\begin{array}{l}\text { Plant defense } \\
\text { elicitor }\end{array}$ & 1003 & 176 & 25 & 0.867235 & 0.191285 \\
\hline SA effects at $4 \mathrm{hr}$ (Van-0) & $\begin{array}{l}\text { Plant defense } \\
\text { elicitor }\end{array}$ & 243 & 66 & 21 & 0.938173 & 0.18619 \\
\hline Pst DC3000 hrpA mutant infection $7 \mathrm{hr}$ & Pathogen infection & 796 & 121 & 20 & 0.947091 & 0.184426 \\
\hline $\begin{array}{l}\text { siz1-3 mutant drought with treatment vs. Col-0 WT with } \\
\text { drought treatment }\end{array}$ & $\begin{array}{l}\text { Plant defense } \\
\text { related mutant }\end{array}$ & 1713 & 244 & 23 & 0.884965 & 0.182514 \\
\hline Pseudomonas syringae pv phaseolicola infiltration for $6 \mathrm{hr}$ & Pathogen infection & 1090 & 161 & 21 & 0.899435 & 0.177085 \\
\hline upf1 mutant vs WT & Others & 268 & 85 & 26 & 0.82047 & 0.176332 \\
\hline WT (Col-0) Bgh infection vs. WT control & Pathogen infection & 2489 & 296 & 20 & 0.924127 & 0.176158 \\
\hline $6 \mathrm{hr}$ control vs $0 \mathrm{hr}$ control & Others & 1128 & 154 & 20 & 0.924756 & 0.174548 \\
\hline shoot under potassium starvation & Others & 1293 & 168 & 20 & 0.929743 & 0.173504 \\
\hline Pst DC3118 Coronatine infection $24 \mathrm{hr}$ & Pathogen infection & 483 & 82 & 18 & 0.955476 & 0.173289 \\
\hline ataf1-1 mutant, Bgh infection vs. ataf1-1 mutant control & Pathogen infection & 3165 & 346 & 19 & 0.938368 & 0.171836 \\
\hline Phytophthora infection for $6 \mathrm{hr}$ & Pathogen infection & 1920 & 237 & 20 & 0.912724 & 0.171609 \\
\hline S15-118 mutant vs. WT & Others & 160 & 63 & 23 & 0.854106 & 0.169901 \\
\hline $\begin{array}{l}\text { Leaf, eds } 16 \text { mutant, Golovinomyces orontii infection for } 5 \mathrm{~d} \text { vs. } \\
\text { eds } 16 \text { mutant, } 0 \mathrm{~d} \text { control }\end{array}$ & Pathogen infection & 152 & 54 & 20 & 0.905124 & 0.166002 \\
\hline 355::ERF104, Flg22 treatment vs. 35S::ERF104, control & $\begin{array}{l}\text { Plant defense } \\
\text { elicitor }\end{array}$ & 1388 & 160 & 18 & 0.95289 & 0.164251 \\
\hline pmr5 mutant vs. WT & $\begin{array}{l}\text { Plant defense } \\
\text { related mutant }\end{array}$ & 93 & 43 & 18 & 0.947634 & 0.16293 \\
\hline E. coli 0157:H7 infection $7 \mathrm{hr}$ & Pathogen infection & 582 & 88 & 18 & 0.940332 & 0.161603 \\
\hline SA effects at $4 \mathrm{hr}($ Kin- 0$)$ & $\begin{array}{l}\text { Plant defense } \\
\text { elicitor }\end{array}$ & 237 & 59 & 19 & 0.919729 & 0.161515 \\
\hline S58-2 mutant vs. WT & Others & 175 & 56 & 20 & 0.892642 & 0.160508 \\
\hline $\begin{array}{l}\text { Leaf, eds 16, Golovinomyces orontii infection for } 7 \mathrm{~d} \text { vs. WT, } \\
\text { infection for } 7 \mathrm{~d}\end{array}$ & $\begin{array}{l}\text { Plant defense } \\
\text { related mutant }\end{array}$ & 455 & 108 & 25 & -0.78266 & 0.158267 \\
\hline Rosette leaf, flu mutant vs. WT & Others & 1024 & 138 & 19 & 0.89576 & 0.157622 \\
\hline Triazolopyrimidine herbicide treatment vs. control & Herbicide & 1768 & 191 & 17 & 0.938601 & 0.156599 \\
\hline $\begin{array}{l}\text { Col-0 WT, Pst DC3000 (avrRpt2) infection vs. uninoculated } \\
\text { control }\end{array}$ & Pathogen infection & 629 & 110 & 21 & 0.827156 & 0.149031 \\
\hline cpr5npr1svi1 triple mutant & $\begin{array}{l}\text { Plant defense } \\
\text { related mutant }\end{array}$ & 388 & 89 & 23 & 0.799919 & 0.14811 \\
\hline DC3000hrpA vs WT at $14 \mathrm{hr}$ pathogen treatment & Pathogen infection & 891 & 107 & 16 & 0.93812 & 0.148062 \\
\hline $2 \mathrm{hr}$ control vs $0 \mathrm{hr}$ control & Others & 864 & 113 & 18 & 0.898938 & 0.146689 \\
\hline OGs effects for $1 \mathrm{hr}$ & $\begin{array}{l}\text { Plant defense } \\
\text { elicitor }\end{array}$ & 866 & 122 & 19 & 0.86349 & 0.145894 \\
\hline $\mathrm{AgNO3}$ & Others & 807 & 117 & 19 & 0.854076 & 0.143679 \\
\hline $\begin{array}{l}\text { Rosette leaf, flu mutant, over-expressing tAPX vs. WT, over- } \\
\text { expressing } t A P X\end{array}$ & Others & 1414 & 149 & 16 & 0.926977 & 0.142656 \\
\hline Elicitor experiment, HrpZ treatment for 2 hr vs. 2 hr control & $\begin{array}{l}\text { Plant defense } \\
\text { elicitor }\end{array}$ & 2043 & 211 & 17 & 0.905002 & 0.142587 \\
\hline Imidazolinone herbicide treatment vs. control & Herbicide & 1843 & 176 & 15 & 0.948063 & 0.14226 \\
\hline flg22 effects for $1 \mathrm{hr}$ & $\begin{array}{l}\text { Plant defense } \\
\text { elicitor }\end{array}$ & 1714 & 180 & 17 & 0.908522 & 0.141837 \\
\hline Pseudomonas syringae pv phaseolicola infiltration for $2 \mathrm{hr}$ & Pathogen infection & 319 & 65 & 18 & 0.869464 & 0.140394 \\
\hline Pst DC3000 infection (5 hr) in wrky17 mutant & Pathogen infection & 2918 & 271 & 16 & 0.918935 & 0.138735 \\
\hline
\end{tabular}


Table 2 The co-regulation T/Cs with expression profiles correlated to the T/C of "16 hr Pseudomonas infection" (A) (Continued)

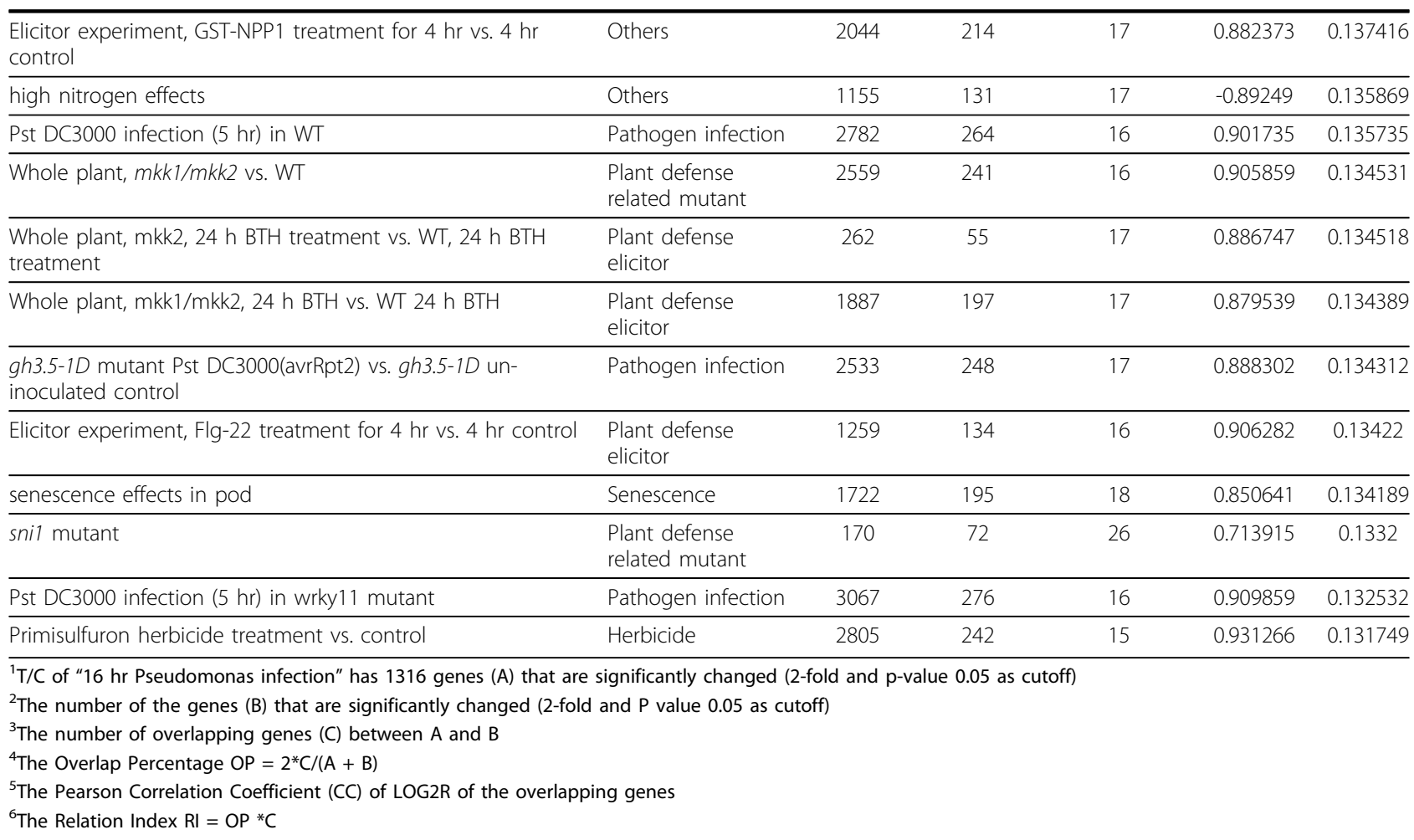

are changed in different slides. With this slide show, users are able to see the change of these 51 selected genes in different $\mathrm{T} / \mathrm{Cs}$. Figures $7 \mathrm{~B}$ to $7 \mathrm{~F}$ reveal changes in the selected genes in the T/Cs with treatments of 6-hr cold, 3-hr cold, 12-hr drought, 12-hr UV-B, and 12-hr wounding, respectively. These slides clearly demonstrate that the selected genes had highest fold changes under 12-hour cold treatment (Figure 7A). The fold-changes decreased in 6-hr (Figure 7B) and 3-hr (Figure 7C) cold treatments. The positions of the 51 selected genes in treatments of drought (Figure 7D), UV-B (Figure 7E) and wounding (Figure 7F) showed less similarity to " $12 \mathrm{hr}$ cold treatment". The Slide View is a very simple and powerful visualization tool for scientists to compare their candidate genes and see how the genes behave differently in the $\mathrm{T} / \mathrm{Cs}$ across studies.

\section{Experiment View}

Experiment View shows experiment title, description/ design, lab information, samples, sample sets, biological replicates, and the definitions of $\mathrm{T} / \mathrm{Cs}$. This view helps users understand the data in detail. For example, the contents of the Experiment View of "Pathogen Series: Pseudomonas half leaf injection" can be seen at the following link http://expressionbrowser.com/arab/displayExperiment.jsp?id=2020113. There are three tabs in the Experiment View. The first tab, called "Details," displays experiment title, description, and other detailed information of the experiment. The second tab " $\mathrm{T} / \mathrm{C}$ " contains information about the $\mathrm{T} / \mathrm{Cs}$ in the experiment. The third tab "Samples and Data" contains information about all sample sets, samples and raw data files. Users can download raw microarray data files through the "Samples and Data" tab and then input these raw data into other microarray data-analysis software to analyze the data and to validate the results obtained from GEB.

\section{Conclusions}

GEB is composed of a data extraction tool, a microarray data-management system, a data annotation tool, a data-processing pipeline, and a search \& visualization tool. The heterogeneity of diverse experimental designs has been greatly mitigated by re-organizing different experimental treatment levels into $\mathrm{T} / \mathrm{Cs}$ so that crossexperimental data integration is easily achieved. GEB separates data processing from interactive display. It pre-processes data and generates data plot images, and then displays the processed data with a web2.0-based interactive user-interface, according to users' requests. This design allows heavy computing to be done offline, and thus allows a large number of data points to be queried quickly and displayed interactively in real-time. GEB displays all data points in one view so that users do not need to scroll down display pages to obtain the 


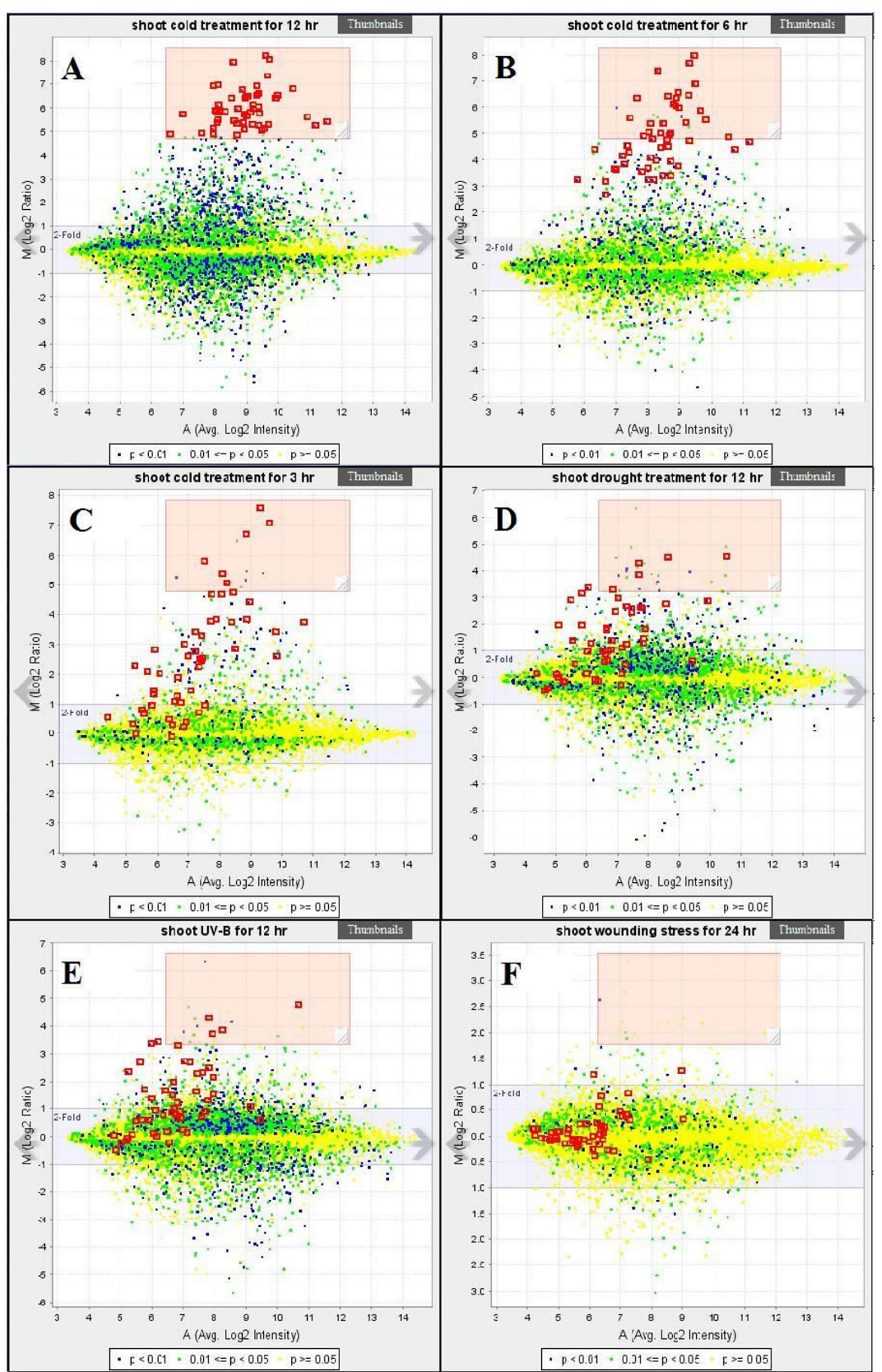

Figure 7 A sample of Slide View for six T/Cs. (3 cold treatments, 1 drought treatment, 1 UV-B treatment, and 1 wounding treatment). Users may test this function at http://www.expressionbrowser.com/arab/displayPairSlides.jsp?id=2055336\& $i d=2055335 \& i d=2055334 \& i d=2055599 \& i d=2055979 \& i d=2056077$. 
trend or pattern of gene expressions from all data points. The highlighting and searching functions in Gene View, T/C View, and Slide View greatly facilitate dynamically exploring the data points based on users' interests. As an additional strategy to improve usability, all raw data and calculated data in GEB are accessible via a full-text search engine. GEB also computes relations of co-regulation $\mathrm{T} / \mathrm{Cs}$ and co-responsive genes. These relations are the foundation for building gene networks and $\mathrm{T} / \mathrm{C}$ networks.

\section{Availability and requirements}

- Project Name: Gene Expression Browser (GEB)

- Public web service: http://www.ExpressionBrowser.com Free and no registration.

- Programming Language: Java, $\mathrm{R}$

- Database: MySQL

- Software License: The software license is owned by GeneExp. GeneExp grants free licenses to non-profit organizations and general licenses to commercial organizations.

- License request: support@ExpressionBrowser.com

\begin{abstract}
Abbreviations
A: Average Log2 Intensity; AJAX: Asynchronous JavaScript and XML; ATH1: A light-regulated Arabidopsis thaliana homeobox 1 gene; BTH:

Benzothiadiazole; CC: Correlation Coefficient; CIBEX: Center for Information Biology Gene Expression Database; CPU: Central Processing Unit; EDS: Enhanced Disease Susceptibility; EBI: The European Bioinformatics Institute; GDS: Granite Data Services; GEB: Gene Express Browser; GEO: Gene Expression Omnibus; JPEG: Joint Photographic Experts Group; LOG2R: Log2 Ratio of Treatment over Control; MA plot: a Quick Overview of Intensitydependent Ratio of Microarray Data; M: LOG2R; N: Nitrogen; NASC: Nottingham Arabidopsis Stock Center; NCBI: The National Center for Biotechnology Information; NIG: The National Institute of Genetics; PR gene: Pathogenesis-related gene; R gene: Resistance genes; Rl: Relation Index; RMA: Robust Multichip Average; SA: Salicylic Acid; SAR: Systemic Acquired Resistance; TAIR: Texas Association for Institutional Research; T/C: Treatment over Control; \%CV: Percentage Coefficient of Variation; OP: Overlapping Percentage; UV-B: Ultraviolet-B Radiation.
\end{abstract}

\section{Acknowledgements}

We thank Dr Michael Gibson for creative discussions on the design of software architecture and user interfaces and for critically reading this paper. We also thank Professor Zhiyong Wang for coining the term "co-responsive genes." Arabidopsis data input and annotation are supported by the Yunnan Advanced Talent Introduction Project Foundation (20080A006), China.

\section{Author details}

${ }^{1}$ GeneExp, 310 South Third Street, San Jose, CA 95112, USA. ${ }^{2}$ Institute of Food Crops, Yunnan Academy of Agricultural Sciences, Kunming 650205, Yunnan Province, China. ${ }^{3}$ Biomatrix, Rockville, MD 20850, USA. ${ }^{4}$ Vice Chancellor, Punjab Agricultural Univ., Ludhiana 141 004, India. ${ }^{5}$ Plant Genetics Research Unit, ARS-USDA, at Donald Danforth Plant Science Center, 975 N. Warson Rd, St. Louis, MO 63132, USA.

\section{Authors' contributions}

MZ, XF, ST proposed software requirements. MZ, YZ, XF, MSK did software specification and design. $Y Z$ developed statistical protocols. MZ designed database schema and developed computational algorithms and the software. LL, LY, ST, JT, WY, YA tested the software application and wrote the manual. MZ downloaded and processed raw microarray data from GEO and NASC. LL, LY, ST, JT, WY annotated the data and nominated the T/CS.
$M Z, Y Z, X F, S T, M S K, Y A$ drafted the manuscript. MZ, YZ, XF, LL, LY, ST, JT, WY, MSK wrote different parts of the manuscript. MZ, YZ, XF, MSK, YA assembled all parts written by different authors together into this manuscript. All authors read and approved this manuscript.

Received: 19 April 2010 Accepted: 20 August 2010

Published: 20 August 2010

\section{References}

1. Chen R, Mallelwar R, Thosar A, Venkatasubrahmanyam S, Butte AJ: GeneChaser: identifying all biological and clinical conditions in which genes of interest are differentially expressed. BMC Bioinformatics 2008, 9:548.

2. Penkett CJ, Bähler J: Navigating public microarray databases. Comparative and Functional Genomics 2004, 5(6-7):471-479.

3. Edgar R, Domrachev M, Lash AE: Gene expression omnibus: NCBI gene expression and hybridization array data repository. Nucleic Acids Research 2002, 30(1):207-210.

4. Brazma A, Sarkans U: Gene Expression Databases. In Nature encyclopedia of the human genome. Edited by: Cooper D. Nature Publishing Group, London; 2003:628-632.

5. Rocca-Serra P, Brazma A, Parkinson H, Sarkans U, Shojatalab M, Contrino S, Vilo J, Abeygunawardena N, Mukherjee G, Holloway E, Kapushesky M, Kemmeren P, Lara GG, Oezcimen A, Sansone S: ArrayExpress: a public database of gene expression data at EBI. Comptes Rendus Biologies 2003, 326(10):1075-1078.

6. Ikeo K, Ishi-i J, Tamura T, Gojobori T, Tateno Y: CIBEX: center for information biology gene expression database. Comptes Rendus Biologies 2003, 326(10):1079-1082.

7. Trivedi P, Edawards JW, Wang JL, Gadbury GL, Srinivasasainagenda V, Zakharkin SO, Kim K, Mehta T, Brand JPL, Patki A, Page GP, Allison DB: HDBStat! A platform-independent software suite for statistical analysis of high dimensional biology data. BMC Bioinformatics 2005, 6:86.

8. Zimmermann P, Hirsch-Hoffmann M, Hennig L, Gruissem W: GENEVESTIGATOR. Arabidopsis microarray database and analysis toolbox. Plant Physiology 2004, 136(1):2621-2632.

9. Craigon DJ, James N, Okyere J, Higgins J, Jotham J, May S: NASCArrays: a repository for microarray data generated by NASC's transcriptomics service. Nucleic Acids Research 2004, 32 Database: D575-D577.

10. Schmid M, Davison TS, Henz SR, Pape UJ, Demar M, Vingron M, Scholkopf B, Weigel D, Lohmann JU: A gene expression map of Arabidopsis thaliana development. Nature Genetics 2005, 37(5):501-506.

11. Kilian J, Whitehead D, Horak J, Wanke D, Weinl S, Batistic O, D'Angelo C, Bornberg-Bauer E, Kudla J, Harter K: The AtGenExpress global stress expression data set: Protocols, evaluation and model data analysis of UV-B light, drought and cold stress responses. The Plant Journal 2007, 50(2):347-363.

12. Ma S, Gong Q, Bohnert HJ: An Arabidopsis gene network based on the graphical Gaussian model. Genome Research 2007, 17(11):1614-1625.

13. Koornneef M, Scheres B: Arabidopsis thaliana as an experimental organism. Encyclopedia of Life Sciences 2001, 1-6.

14. Agrawal GK, Yonekura M, Iwahashi Y, Iwahashi H, Rakwal R: System, trends and perspectives of proteomics in dicot plants. Part I: Technologies in proteome establishment. Journal of Chromatography. B, Analytical Technologies in the Biomedical and Life Sciences 2005, 815(1-2):109-123.

15. Irizarry RA, Hobbs B, Collin F, Beazer-Barclay YD, Antonellis KJ, Scherf U, Speed TP: Exploration, normalization, and summaries of high density oligonucleotide array probe level data. Biostatistics 2003, 4(2):249-264.

16. Dudoit $S$, Yang YH, Callow MJ, Speed TP: Statistical methods for identifying differentially expressed genes in replicated CDNA microarray experiments. Statistica Sinica 2002, 12(1):111-140.

17. Bolstad BM, Irizarry RA, Astrand M, Speed TP: A comparison of normalization methods for high density oligonucleotide array data based on variance and bias. Bioinformatics 2003, 19(2):185-193.

18. Garrett JJ: Ajax: A new approach to web application. 2005 [http://www. adaptivepath.com/ideas/essays/archives/000385.php].

19. Cao H, Glazebrook J, Clark JD, Volko S, Dong X: The Arabidopsis NPR1 gene that controls systemic acquired resistance encodes a novel protein containing ankyrin repeats. Cell 1997, 88(1):57-63.

20. Durner J, Shah J, Klessig DF: Salicylic acid and disease resistance in plants. Trends in Plant Science 1997, 2(7):266-274. 
21. De Vos M, Van Zaanen W, Koornneef A, Korzelius JP, Dicke M, Van Loon LC, Pieterse CM: Herbivore-induced resistance against microbial pathogens in Arabidopsis. Plant Physiology 2006, 142(1):352-363.

22. Rivière MP, Marais $A$, Ponchet $M$, Willats $W$, Galiana E: Silencing of acidic pathogenesis-related PR-1 genes increases extracellular beta- $(1 \rightarrow 3)$ glucanase activity at the onset of tobacco defence reactions. Journal of Experimental Botany 2008, 59(6):1225-1239.

23. Bowles JD: Defense-related proteins in higher plants. Annual Review of Biochemistry 1990, 59:873-907.

24. Boller T: Antimicrobial functions of the plant hydrolases chitinase and $\beta$ 1,3-glucanase. In Developments In Plant Pathology. Edited by: Fritig B, Legrand M. Springer, New York; 1993:391-400.

25. Stone BA, Clarke AE: $(1,3)-\beta$-glucans in plant host-pathogen interactions. Chemistry and biology of (1,3)- $\beta$-glucan La Trobe University Press, Bundoora, Australia 1992, 491-512.

26. Morris SW, Vernooij B, Titatarn S, Starrett M, Thomas S, Wiltse CC, Frederiksen RA, Bhandhufalck A, Hulbert S, Uknes S: Induced resistance responses in maize. Molecular Plant Microbe Interactions 1998, 11(7):643-658.

27. Wildermuth MC, Dewdney J, Wu G, Ausubel FM: Isochorismate synthase is required to synthesize salicylic acid for plant defence. Nature 2001, 414(6863):562-565.

28. Meier $\mathrm{S}$, Gehring $\mathrm{C}$ : A guide to the integrated application of on-line data mining tools for the inference of gene functions at the systems level. Biotechnology Journal 2008, 3(11):1375-1387.

29. Glazebrook J: Genes controlling expression of defense responses in Arabidopsis-2001 status. Current Opinion in Plant Biology 2001, 4(4):301-308.

30. Venugopal1 SC, Jeong R, Mandal MK, Zhu SF, Chandra-Shekara1 AC, Xia Y, Hersh M, Stromberg AJ, Navarre D, Kachroo A, Kachroo P: Enhanced Disease Susceptibility 1 and Salicylic Acid Act Redundantly to Regulate Resistance Gene-Mediated Signaling. PLoS Genet 2009, 5(7):e1000545.

31. Falk A, Feys BJ, Frost LN, Jones JD, Daniels MJ, Parker JE: EDS1, an essential component of $\mathrm{R}$ gene-mediated disease resistance in Arabidopsis has homology to eukaryotic lipases. Proceedings of the National Academy of Sciences of the United States of America 1999, 96(6):3292-3297.

32. Nawrath C, Heck S, Parinthawong N, Metraux JP: EDS5, an essential component of salicylic acid-dependent signaling for disease resistance in Arabidopsis, is a member of the MATE transport family. Plant Cell 2002, 14(1):275-286.

33. Hoffland E, Jeger MJ, Van Beusichem ML: Effect of nitrogen supply rate on disease resistnce in tomato depends on the pathogen. Plant and Soil 2000, 218(1-2):239-248.

34. Freeman TC, Goldovsky L, Brosch M, Dongen SV, Maziere P, Grocock RJ, Freilich S, Thornton J, Enright AJ: Construction, visualization, and clustering of transcription networks from microarray expression data. PLoS Computational Biology 2007, 3(10):e206.

35. Theocharidis T, Dongen SV, Enright AJ, Freeman T: Network visualization and analysis of gene expression data using BioLayout Express ${ }^{3 \mathrm{D}}$. Nature Protocols 2009, 4(10):1535-1550.

doi:10.1186/1471-2105-11-433

Cite this article as: Zhang et al:: Gene Expression Browser: large-scale and cross-experiment microarray data integration, management, search \& visualization. BMC Bioinformatics 2010 11:433.

\section{Submit your next manuscript to BioMed Central and take full advantage of:}

- Convenient online submission

- Thorough peer review

- No space constraints or color figure charges

- Immediate publication on acceptance

- Inclusion in PubMed, CAS, Scopus and Google Scholar

- Research which is freely available for redistribution

Submit your manuscript at www.biomedcentral.com/submit
Biomed Central 